Check for updates

Cite this: RSC Adv., 2019, 9, 65

\title{
Large magnetocaloric entropy change at room temperature in soft ferromagnetic manganites
}

\begin{abstract}
Souhir Bouzidi, ${ }^{a}$ Mohamed Amara Gdaiem, (D) *a J. Dhahri ${ }^{\mathrm{a}}$ and E. K. Hlil ${ }^{\mathrm{b}}$
In this paper, $\mathrm{La}_{0.75} \mathrm{Ca}_{0.25-x} \mathrm{Na}_{x} \mathrm{MnO}_{3}(x=0.15$ and 0.20$)$ samples were prepared by the flux method. Crystallographic study revealed that the $x=0.15$ sample is characterized by the coexistence of a mixture of orthorhombic and rhombohedral structures with Pbnm and $R \overline{3} c$ space groups, respectively. While, the $x=$ 0.20 sample crystallized in the rhombohedral structure with a $R \overline{3} c$ space group. Magnetic data, under a magnetic field of $0.05 \mathrm{~T}$, indicated that our samples undergo a ferromagnetic (FM)-paramagnetic (PM) phase transition, on increasing the temperature. The magnetic field dependence of the magnetocaloric properties of $\mathrm{La}_{0.75} \mathrm{Ca}_{0.25-x} \mathrm{Na}_{x} \mathrm{MnO}_{3}(x=0.15$ and 0.20$)$ samples, with the second phase transition, was investigated. Near room temperature, the $x=0.20$ sample exhibited a large magnetic entropy change with maxima of 6.01 and $3.12 \mathrm{~J} \mathrm{~kg}^{-1} \mathrm{~K}^{-1}$, respectively, under applied magnetic fields of 5 and $2 \mathrm{~T}$. Also, the relative cooling power (RCP) was calculated. According to hysteresis cycles, for our studied samples, at 10 $\mathrm{K}$ a typical soft FM behavior with a low coercive field was observed. These results make our samples promising candidates for magnetic refrigerators, magnetic recording, and memory devices.
\end{abstract}

Received 5th November 2018 Accepted 10th December 2018

DOI: $10.1039 / \mathrm{c} 8 \mathrm{ra0} 09166 \mathrm{~h}$

rsc.li/rsc-advances dependent on the substitution rate $x$, average size of the cation, cationic disorder and the elaboration method. ${ }^{10} \mathrm{La}_{1-x} \mathrm{Ca}_{x} \mathrm{MnO}_{3}$ has attracted the attention of several researchers. This is thanks to the very rich phase diagram observed in this series. ${ }^{11,12}$ Pekala et al. ${ }^{13}$ investigated its magnetic field dependence of electrical resistivity in fine grains and analyzed the influence of external magnetic field on the transport processes in detail. Yi et al. ${ }^{14}$ observed that the magnetoresistance of nanosized $\mathrm{La}_{0.75^{-}}$ $\mathrm{Ca}_{0.25} \mathrm{MnO}_{3}$ is enhanced at low temperatures due to the spinpolarized tunneling behavior. In addition, the pressure dependence of magnetic phase separation and transport behavior in $\mathrm{La}_{0.75} \mathrm{Ca}_{0.25} \mathrm{MnO}_{3}$ has also been investigated in recent paper. ${ }^{15}$ On other hand, with the substitution of $\mathrm{Na}$ on $\mathrm{LaMnO}_{3}$ sample, an amount $2 \times$ of $\mathrm{Mn}^{3+}$ is converted to $\mathrm{Mn}^{4+}$. Zhong et al. ${ }^{16}$ have studied the magnetocaloric properties in $\mathrm{La}_{1-x} \mathrm{Na}_{x} \mathrm{MnO}_{3}(0 \leq x$ $\leq 0.2$ ) and found that for $x=0.2,\left|-\Delta S_{\mathrm{M}}^{\max }\right|$ reaches $1.96 \mathrm{~J} \mathrm{~kg}^{-1}$ $\mathrm{K}^{-1}$ upon a magnetic applied field change of $1 \mathrm{~T}$. This paper investigates the effect of $\mathrm{Na}$ substitution on the structural, magnetic and magnetocaloric effect (MCE) of $(x=0.15$ and 0.20) samples, synthesized by flux method, using sodium chloride $(\mathrm{NaCl})$ as a flux. A theoretical investigation was used to predict the MCE properties for $x=0.20$.

\section{Experimental details}

Generally, ceramic materials are highly affected by the preparation routes and heat treatments. The synthesis methods based on the conventional ceramic or solid state reaction are not suitable for advanced technological applications, as these methods produce particles of large size at high temperatures.

\footnotetext{
${ }^{a}$ Laboratoire de la Matière Condensée et des Nanosciences, Département de Physique Faculté des Sciences de Monastir, Avenue de l'Environnement, Monastir- 5019, Tunisia. E-mail: gdaiem_mohamed@hotmail.fr; Fax: +21673500280; Tel: $+21656350636$

${ }^{b}$ Institut Néel, CNRS et Université Joseph Fourier, BP 166, F-38042, Grenoble Cedex 9, France
} 
Alternatively, to produce a very high-quality, homogenous and nano-polycrystalline powder of $\mathrm{La}_{0.75} \mathrm{Ca}_{0.25-x} \mathrm{Na}_{x} \mathrm{MnO}_{3}(x=0.15$ and 0.20) compounds, at low temperature, we used the flux method, $\mathrm{NaCl}$ as a flux. The scheme of the synthetic route is to take stoichiometric amounts of high purity $\mathrm{La}_{2} \mathrm{O}_{3}, \mathrm{MnO}_{2}$ and $\mathrm{CaCO}_{3}$ in the appropriate molar ratio. The last mixture was ground, for half an hour, with an appropriate quantity of $\mathrm{NaCl}$ in an agate mortar. Then, the mixture was heated at $800{ }^{\circ} \mathrm{C}$ for $24 \mathrm{~h}$ in a recrystallized alumina crucible. After that, the melt was washed with distilled water and filtrated in order to remove easily the residual salts. The resulting powder was dried at $110^{\circ} \mathrm{C}$ for $3 \mathrm{~h}$ and heated at $800^{\circ} \mathrm{C}$ for $6 \mathrm{~h}$. Finally, the powder was pressed into disks under 5 tonnes per $\mathrm{cm}^{2}$ and sintered at $800{ }^{\circ} \mathrm{C}$. In order to characterize our samples we carried out, at room temperature, the phase purity by powder X-ray diffraction (XRD) using a Panalytical X pert Pro-diffractometer with $\mathrm{Cu}-\mathrm{K}_{\alpha}$ radiation $(\lambda=1.5406 \AA)$. Data refinement was obtained with $2 \theta$ from 10 and $100^{\circ}$ with a step size of 0.017 and a step time of $18 \mathrm{~s}$. The microstructure was determined, at room temperature, by a scanning electron microscope (SEM) using a Philips XL30. The compositions of our samples were obtained by a semiquantitative analysis performed at $20 \mathrm{kV}$ accelerating voltage using energy dispersive X-ray analysis (EDX). The magnetic analysis was carried out using BS1 and BS2 magnetometers developed in Louis Neel Laboratory of Grenoble.

\section{Results and discussion}

\subsection{X-Ray diffraction study}

To analyze the structural properties of our samples, we carried out XRD analysis with $\mathrm{CuK} \alpha$ radiation at room temperature. The data were analyzed by Rietveld method using Fullprof program. ${ }^{17}$ Fig. 1 (a) and (b) exemplifies the Rietveld refinement of XRD profile, for the $x=0.15$ and 0.20 samples, respectively. A
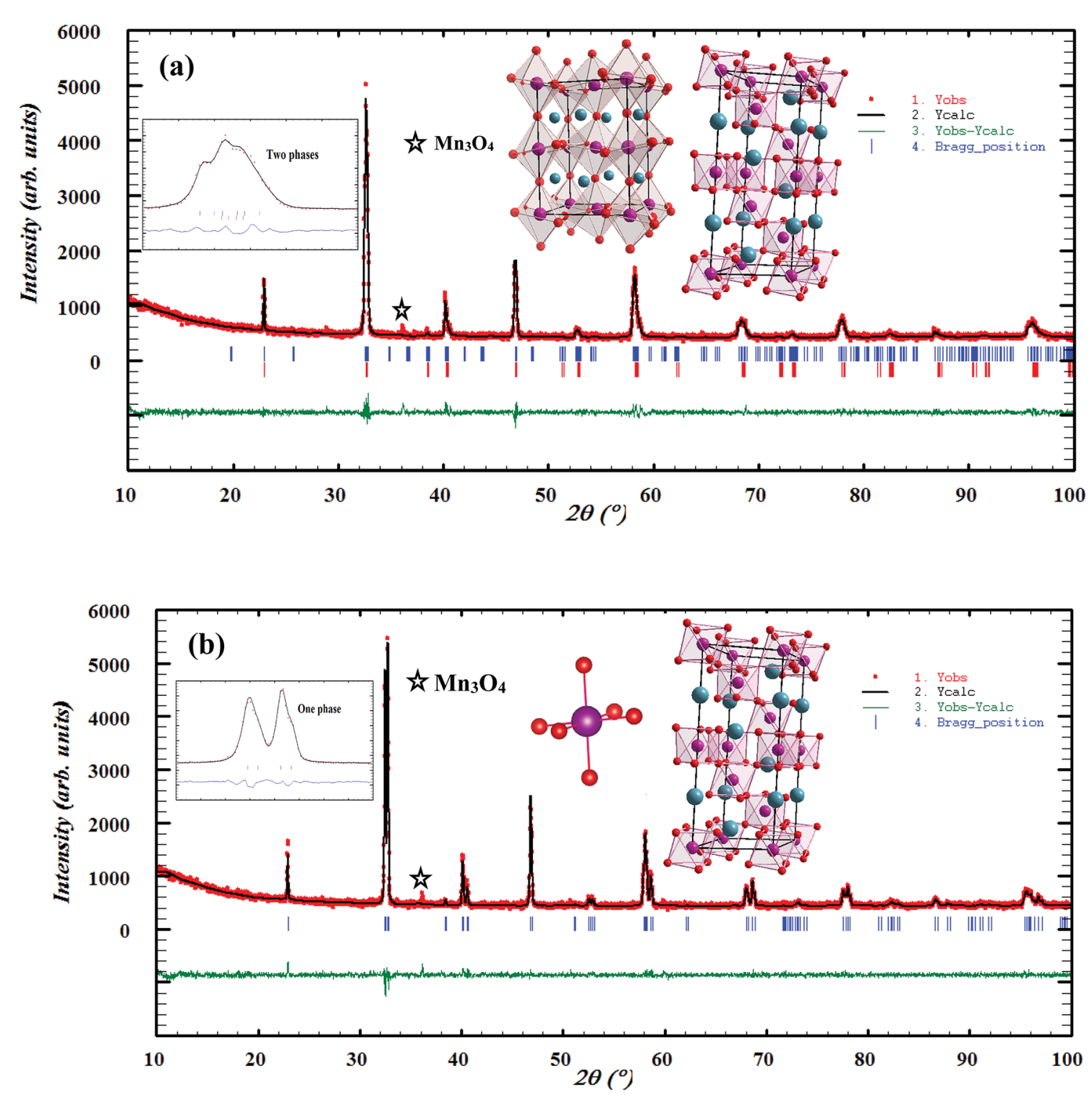

Fig. 1 Observed and calculated (solid line) of XRD patterns of $\mathrm{La}_{0.75} \mathrm{Ca}_{0.25-x} \mathrm{Na}_{x} \mathrm{MnO}_{3}(x=0.15$ and 0.20 ) compounds. The vertical bars show the Bragg peak positions and the bottom of the figure shows the difference between the observed and the calculated patterns. The insets show the crystal structure of our samples. 
good agreement between the observed and the calculated profiles was remarked. This is due to the excellent goodness of fit $\left(\chi^{2}\right)$, confirming the high quality of refinement. From this figure, we can deduce that the $x=0.15$ sample is a mixture of orthorhombic and rhombohedral structures, respectively, with $P b n m$ and $R \overline{3} c$ space groups, around $2 \theta=32^{\circ}$. In this region, the system showed a sign of multi-phased behavior with no complete splitting into the double line of the intense peak. This result is in concordance with that observed in ref. 18 . The relative amount of the orthorhombic phase was $81.68 \%$. However, that of the rhombohedral phase was $18.32 \%$. We can conclude that the orthorhombic phase is dominant. On the other hand, $x=0.20$ sample crystallized in the rhombohedral structure with $R \overline{3} c$ space group. Also, we can see the appearance of a small quantity of $\mathrm{Mn}_{3} \mathrm{O}_{4}$, as found in recent works. ${ }^{19,20}$

The different fitting parameters of our samples are summarized in Table 1 . According to Shannon, ${ }^{21}$ the ionic radius of $\mathrm{Na}^{+}\left(r_{\mathrm{Na}}{ }^{+}=1.24 \AA\right)$ is higher than that of $\mathrm{Ca}^{2+}\left(r_{\mathrm{Ca}}{ }^{2+}=\right.$ $1.18 \AA$ ). This can be explained by the slight increase of the lattice size with increasing $\mathrm{Na}$ content. It has been reported that the deformation of the $\mathrm{MnO}_{6}$ octahedron may be responsible for the distortion in the perovskite structures. The crystal

Table 1 Refined structural parameters for $\mathrm{La}_{0.75} \mathrm{Ca}_{0.25-x} \mathrm{Na}_{x} \mathrm{MnO}_{3}(x=$ 0.15 and 0.20 ) samples determined from $X$-ray after the Rietveld refinement at room temperature

\begin{tabular}{|c|c|c|c|}
\hline & $x=0.15$ & & $x=0.20$ \\
\hline Space group & Pbnm & $R \overline{3} c$ & $R \overline{3} c$ \\
\hline$a(\AA)$ & $5.502(5)$ & $5.482(4)$ & $5.508(6)$ \\
\hline$b(\AA)$ & $5.461(5)$ & $5.482(4)$ & $5.508(6)$ \\
\hline$c(\AA)$ & $7.751(8)$ & $13.406(3)$ & $13.331(9)$ \\
\hline$V\left(\AA^{3}\right)$ & 232.963 & 348.975 & 350.357 \\
\hline \multicolumn{4}{|l|}{$\mathrm{La} / \mathrm{Ca} / \mathrm{Na}$} \\
\hline$x$ & $0.498(9)$ & & 0.0000 \\
\hline$y$ & $0.013(1)$ & & 0.0000 \\
\hline$z$ & 0.2500 & & 0.2500 \\
\hline$B_{\text {iso }}\left(\AA^{2}\right)$ & $1.16(3)$ & & $1.08(2)$ \\
\hline \multicolumn{4}{|l|}{$\mathrm{Mn}$} \\
\hline$B_{\text {iso }}\left(\AA^{2}\right)$ & $0.66(2)$ & & $0.68(4)$ \\
\hline \multicolumn{4}{|l|}{$\mathrm{O}_{1}$} \\
\hline$x$ & $0.226(7)$ & & $0.443(8)$ \\
\hline$y$ & $0.306(5)$ & & 0.0000 \\
\hline$z$ & $0.008(9)$ & & 0.2500 \\
\hline$B_{\text {iso }}\left(\AA^{2}\right)$ & $1.45(2)$ & & $1.51(3)$ \\
\hline \multicolumn{4}{|l|}{$\mathrm{O}_{2}$} \\
\hline$x$ & $0.576(8)$ & & - \\
\hline$y$ & $0.494(6)$ & & - \\
\hline$z$ & 0.2500 & & - \\
\hline$B_{\text {iso }}\left(\AA^{2}\right)$ & $1.41(5)$ & & - \\
\hline \multicolumn{4}{|l|}{ Discrepancy factors } \\
\hline$R_{\mathrm{p}}(\%)$ & 4.38 & 4.05 & 3.83 \\
\hline$R_{\mathrm{wp}}(\%)$ & 5.82 & 5.16 & 4.87 \\
\hline$\chi^{2}$ & 1.81 & 1.40 & 1.30 \\
\hline \multicolumn{4}{|c|}{ Bond lengths and bond angles } \\
\hline$\theta_{\mathrm{Mn}-\mathrm{O}_{1}-\mathrm{Mn}}\left({ }^{\circ}\right)$ & 161.31 & & - \\
\hline$\theta_{\mathrm{Mn}-\mathrm{O}_{2}-\mathrm{Mn}}\left({ }^{\circ}\right)$ & 155.34 & & - \\
\hline$\left\langle\theta_{\mathrm{Mn}-\mathrm{O}-\mathrm{Mn}}\right\rangle\left(^{\circ}\right)$ & 158.32 & & 161.90 \\
\hline$d_{\mathrm{Mn}-\mathrm{O}_{1}}(\AA)$ & $2.09(2)$ & & - \\
\hline$d_{\mathrm{Mn}-\mathrm{O}_{2}}(\AA)$ & $1.98(3)$ & & - \\
\hline$\left\langle d_{\mathrm{Mn}-\mathrm{O}}\right\rangle(\AA)$ & $2.03(7)$ & & $1.96(4)$ \\
\hline Bandwidth $W\left(10^{-2}\right)$ (u.a.) & 8.1 & & 9.3 \\
\hline Tolerance factor $T_{\mathrm{G}}$ & 0.9758 & & 0.9795 \\
\hline
\end{tabular}

structures and the $\mathrm{MnO}_{6}$ octahedron for the samples $(x=0.15$ and 0.20 ) were drawn using the VESTA program (inset of Fig. 1(a) and (b)). ${ }^{22}$ To better understand the regularities governing the formation of perovskite-type systems, Goldschmidt's tolerance factor, $T_{\mathrm{G}}$, is usually introduced. It is defined by the following expression: ${ }^{23,24}$

$$
T_{\mathrm{G}}=\frac{\left\langle r_{(\mathrm{La}, \mathrm{Ca}, \mathrm{Na})}\right\rangle+\left\langle r_{\mathrm{O}}\right\rangle}{\sqrt{2}\left(\left\langle r_{\mathrm{Mn}}\right\rangle+\left\langle r_{\mathrm{O}}\right\rangle\right)}
$$

where $r_{(\mathrm{La}, \mathrm{Ca}, \mathrm{Na})}, r_{\mathrm{O}}$ and $r_{\mathrm{Mn}}$ are the ionic radii of the different elements. The manganese oxide compounds have a perovskite structure if $0.89<T_{\mathrm{G}}<1.02 .^{25}$ The obtained values of $T_{\mathrm{G}}$ for our samples were listed in Table 1 . This confirmed the stability of this structure.

The experimental density $\left(D_{\text {exp }}\right)$ is determined from the weight and geometrical dimensions of the cylindrical pellets. ${ }^{26}$ It was found to be 5.963 and $5.958 \mathrm{~g} \mathrm{~cm}^{-3}$, respectively, for $x=$ 0.15 and 0.20 samples.

The XRD density ( $D_{\mathrm{XRD}}$ ) of our samples is determined from $\mathrm{X}$-ray measurements. ${ }^{26}$ It was found to be 6.085 and $6.081 \mathrm{~g} \mathrm{~cm}^{-3}$ for $x=0.15$ and 0.20 , respectively. These values are in agreement with those obtained in other manganites. ${ }^{27,28}$ The compactness $^{26}$ is thus calculated, the obtained values are $98 \%$ and $97 \%$ for $x=0.15$ and 0.20 samples, respectively.

\subsection{Morphological study}

From the reflection of $2 \theta$ values of XRD profile, the crystallite size $(D)$ was calculated using Scherer's equation (eqn (2)):

$$
D=\frac{K \lambda}{\beta \cos (\theta)},
$$

where $K$ is the shape factor, which usually takes a value of about $0.9, \lambda=1.5406 \AA$ is the wavelength for $\mathrm{CuK}_{\alpha}$ radiation, $\theta$ is the diffraction angle of the most intense peak and $\beta$ is the full width at half maximum of the highest peak. $D$ values are listed in Table 2 . The obtained values are comparable with those reported in the literature. ${ }^{26-30}$ Regarding the SEM micrograph, insets (a) and (b) of Fig. 2, show a homogenous microstructure and a uniform grain size distribution, for $x=0.15$ as an example. The grain sizes were estimated to be mostly within 2.12 and $2.14 \mu \mathrm{m}$ for $x=0.15$ and 0.20 , respectively. Obviously, the particle sizes observed by SEM were much larger than those calculated using Scherer's formula. This indicates that each grain observed by SEM consists of several crystallites. ${ }^{31,32}$

In order to check the existence of all elements in $\mathrm{La}_{0.75^{-}}$ $\mathrm{Ca}_{0.25-x} \mathrm{Na}_{x} \mathrm{MnO}_{3}(x=0.15$ and 0.20$)$ compounds, EDX analysis was performed. The EDX spectrum, for $x=0.15$ as an example, is shown in Fig. 2, The typical cationic compositions are listed in Table 3. It is clear that all elements ( $\mathrm{La}, \mathrm{Ca}, \mathrm{Na}, \mathrm{Mn}$, and O)

Table 2 Average crystallite size determined by Scherrer's formula and SEM

\begin{tabular}{lll}
\hline Samples & $x=0.15$ & $x=0.20$ \\
$\left\langle r_{\mathrm{A}}\right\rangle(\AA)$ & 1.362 & 1.365 \\
$D_{\text {Sch }}(\mathrm{nm})$ & 49.38 & 50.71 \\
$D_{\text {SEM }}(\mu \mathrm{m})$ & 2.12 & 2.14
\end{tabular}




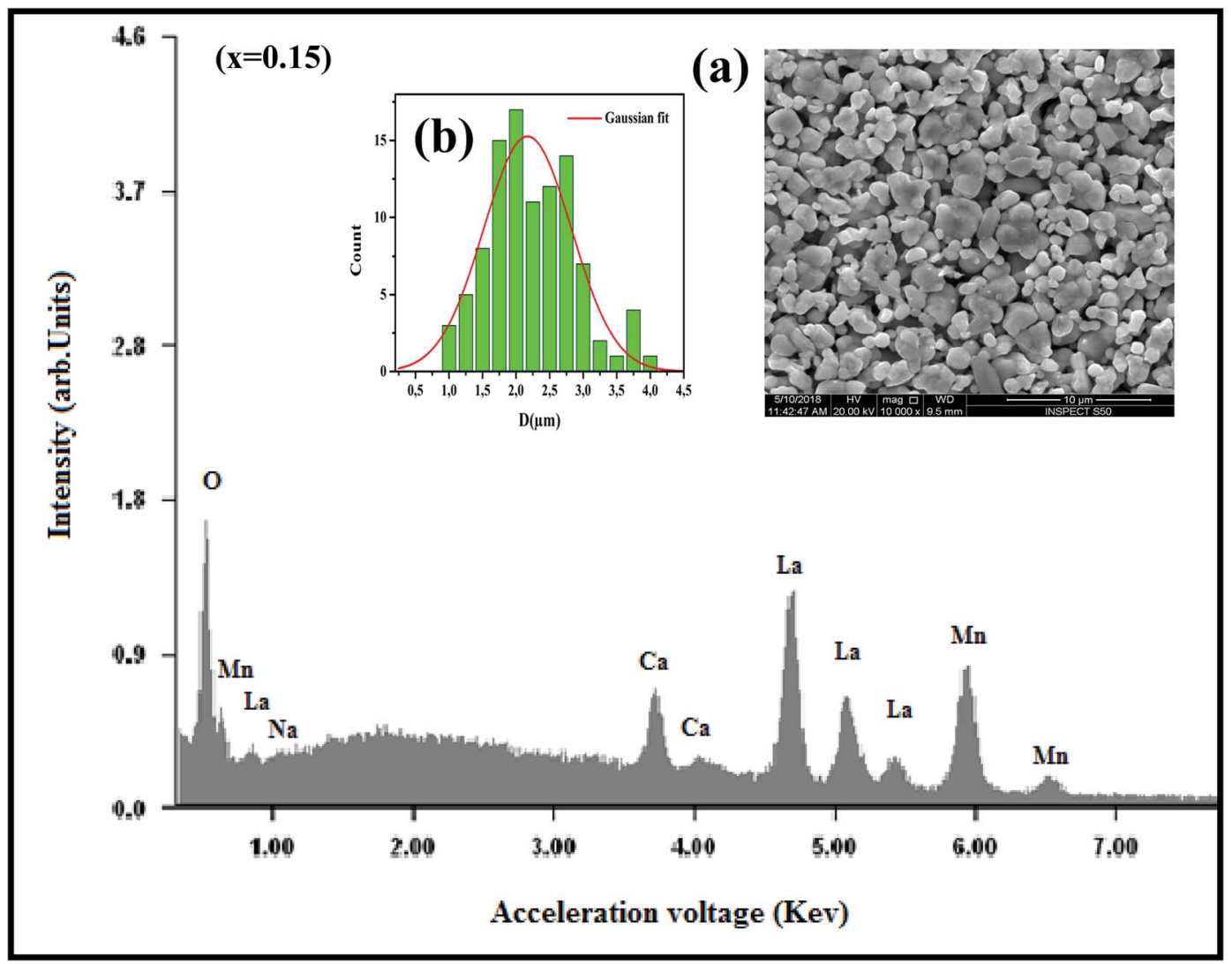

Fig. 2 The EDX analysis for $x=0.15$ sample. Insets: (a) shows the typical SEM and (b) shows the histogram of the distribution of particle size.

are present with no loss of any integrated elements during the sintering process.

\subsection{Magnetic study}

Following the Morphological study, we discussed the thermal variation of the magnetic properties of $\mathrm{La}_{0.75} \mathrm{Ca}_{0.25-x} \mathrm{Na}_{x} \mathrm{MnO}_{3}$ $(x=0.15$ and 0.20$)$. Fig. 3(a) and (b) shows the zero-field-cooled (ZFC) and field-cooled (FC) magnetizations of our samples under an applied field of $0.05 \mathrm{~T}$ in the temperature range 5 to $400 \mathrm{~K}$. We can remark a net PM-FM transition, at their $T_{\mathrm{C}}$. A small divergence between ZFC and FC plots can be observed at the irreversibility temperature $T=270$ and $250 \mathrm{~K}$, respectively for $x=0.15$ and 0.20 . This phenomenon can be attributed to the appearance of an isotropic field generated from FM clusters. ${ }^{32}$ At low temperatures, a small peak was observed around $40 \mathrm{~K}$. This indicates the appearance of $\mathrm{Mn}_{3} \mathrm{O}_{4}$ phase. ${ }^{33,34} T_{\mathrm{C}}$ can be determined from $\mathrm{d}^{2} M / \mathrm{d} T^{2}(T)$ graphs (Fig. 3(a) and (b)). From this figure, we remarked the appearance of different inflection

Table 3 Results of EDX analysis

\begin{tabular}{lllll}
\hline & \multicolumn{4}{l}{ Typical cationic composition from EDX } \\
\cline { 2 - 5 } Nominal composition & $\mathrm{La}$ & $\mathrm{Ca}$ & $\mathrm{Na}$ & $\mathrm{Mn}$ \\
\hline $\mathrm{La}_{0.75} \mathrm{Ca}_{0.10} \mathrm{Na}_{0.15} \mathrm{MnO}_{3}$ & 0.751 & 0.101 & 0.149 & 1.000 \\
$\mathrm{La}_{0.75} \mathrm{Ca}_{0.05} \mathrm{Na}_{0.20} \mathrm{MnO}_{3}$ & 0.750 & 0.049 & 0.201 & 1.001
\end{tabular}

points. For the $x=0.20$ sample, a classical behavior at $300 \mathrm{~K}$ was observed, corresponding to its $T_{\mathrm{C}}$. While the $x=0.15$ sample presented two inflection points, around room temperature, corresponding to two Curie temperatures. This can be interpreted by the presence of two different FM phases. The Curie temperatures were measured at $T_{\mathrm{C} 1}=273 \mathrm{~K}$ and $T_{\mathrm{C} 2}=301.5 \mathrm{~K}$. Additionally, we can see a slight decrease of $T_{\mathrm{C}}$ with increasing $\mathrm{Na}^{+}$content. According to Asma Zaidi et al. ${ }^{35}$ the decrease of $T_{\mathrm{C}}$ can be interpreted in terms of the increase in $\mathrm{Mn}^{4+}$ content above $40 \%$, which produces a decrease in the $\mathrm{DE}$ interaction $\left(\mathrm{Mn}^{3+}-\mathrm{O}^{2-}-\mathrm{Mn}^{4+}\right)$ and enhances the SE interaction $\left(\mathrm{Mn}^{4+}-\mathrm{O}^{2-}\right.$ $\mathrm{Mn}^{4+}$ ). Here, we can discuss the evolution of the bandwidth using eqn (3)

$$
W_{\mathrm{b}} \approx \frac{\cos w}{d_{(\mathrm{Mn}-\mathrm{O})}^{3.5}},
$$

where $w=1 / 2(\pi-\langle\mathrm{Mn}-\mathrm{O}-\mathrm{Mn}\rangle)$ and $d_{(\mathrm{Mn}-\mathrm{O})}$ is the bond length characterized by the overlap between $\mathrm{Mn}_{3 \mathrm{~d}}$ and $\mathrm{O}_{2 \mathrm{p}}$ orbitals. ${ }^{36}$ The calculated $W_{\mathrm{b}}$ values are tabulated in Table 1 .

To understand the dynamics of spin, we carried out the inverse of susceptibility as function of temperatures, as shown in Fig. 4. In PM region, $\chi^{-1}$ can be fitted by Curie-Weiss (CW) law. ${ }^{37}$ Fitting the linear part; we get the $\theta_{\mathrm{p}}$ values (Table 4$)$. It is worth to mentioning that $\theta_{\mathrm{p}}$ values can be negative, positive or null according to AFM, FM or PM behavior, respectively. In our case, $\theta_{\mathrm{p}}$ values are positive, confirming the FM behavior. It is clear that the $\theta_{\mathrm{p}}$ value is higher than $T_{\mathrm{C}}$. This can be interpreted 

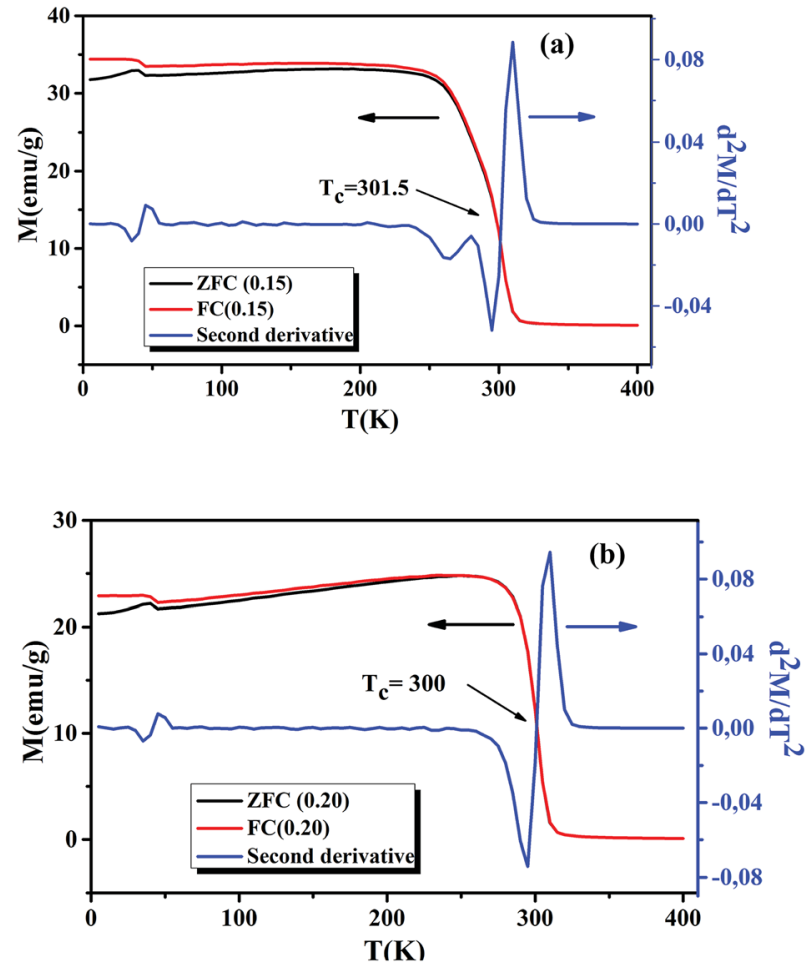

Fig. 3 Temperature dependence of the ZFC and FC magnetization and $d^{2} M / d T^{2}$ plots for $\mathrm{La}_{0.75} \mathrm{Ca}_{0.25-x} \mathrm{Na}_{x} \mathrm{MnO}_{3}(x=0.15$ and 0.20 ) compounds, under a magnetic field of $0.05 \mathrm{~T}$.

by the magnetic inhomogeneity above $T_{\mathrm{C}} \cdot{ }^{38}$ The experimental effective moment $\left(\mu_{\text {eff }}^{\text {exp }}\right)$ and the theoretical effective moment $\left(\mu_{\mathrm{eff}}^{\text {theo }}\right)$ are, also, calculated. The obtained values of $\mu_{\mathrm{eff}}^{\exp }$ and $\mu_{\text {eff }}^{\text {theo }}$ are listed in Table 4 . We can notice that the difference between the experimental and the theoretical values is attributed to the FM correlations in PM region. These are probably due to the formation of FM cluster. ${ }^{39}$ Our results are comparable with other works. ${ }^{\mathbf{4 0 , 4 1}}$ In addition, it is important to mention that the percentage of $\mathrm{Mn}^{3+}$ and $\mathrm{Mn}^{4+}$ ions can be checked quantitatively by the so-called chemical titration. To verify these

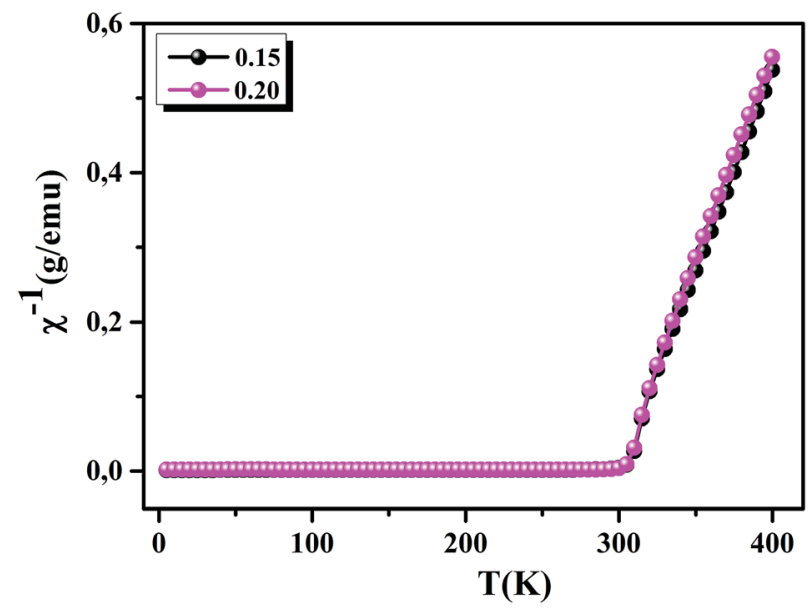

Fig. 4 Inverse of susceptibility as a function of temperatures for $\mathrm{La}_{0.75} \mathrm{Ca}_{0.25-x} \mathrm{Na}_{x} \mathrm{MnO}_{3}(x=0.15$ and 0.20$)$ samples determined in a field of $0.05 \mathrm{~T}$.
Table 4 Some experimental values for $\mathrm{La}_{0.75} \mathrm{Ca}_{0.25-x} \mathrm{Na}_{x} \mathrm{MnO}_{3}(x=$ 0.15 and 0.20 ) compounds

\begin{tabular}{lll}
\hline & $x=0.15$ & $x=0.20$ \\
\hline$T_{\mathrm{C}}(\mathrm{K})$ & 301.5 & 300 \\
$\theta_{\mathrm{p}}(\mathrm{K})$ & 301,66 & 301,11 \\
$\mu_{\text {effo }}^{\text {theo }}\left(\mu_{\mathrm{B}}\right)$ & 4.51 & 4.46 \\
$\mu_{\text {eff }}^{\text {exp }}\left(\mu_{\mathrm{B}}\right)$ & 5.62 & 5.33
\end{tabular}

percentages, we carried out a chemical analysis. In fact, our obtained powder was dissolved in concentrated sulfuric acid and oxalic acid dihydrate. The obtained solution is titrated by potassium permanganate and the values of manganese ions concentration are $\left(\mathrm{Mn}^{3+}=60.1 \%\right)$ and $\left(\mathrm{Mn}^{4+}=39.9 \%\right)$ for $x=$ 0.15 and $\left(\mathrm{Mn}^{3+}=54.8 \%\right)$ and $\left(\mathrm{Mn}^{4+}=45.2 \%\right)$ for $x=0.20$. In order to get a deeper insight into the magnetic properties at low temperatures, we analysed the hysteresis cycles $M\left(\mu_{0} H\right)$. Fig. 5(a) and (b) displays $M\left(\mu_{0} H\right)$ at $10 \mathrm{~K}, \mu_{0} H= \pm 6 \mathrm{~T}$. We remarked clearly that the curves are quite similar to each other with a small hysteresis loop. In the weak field region at low
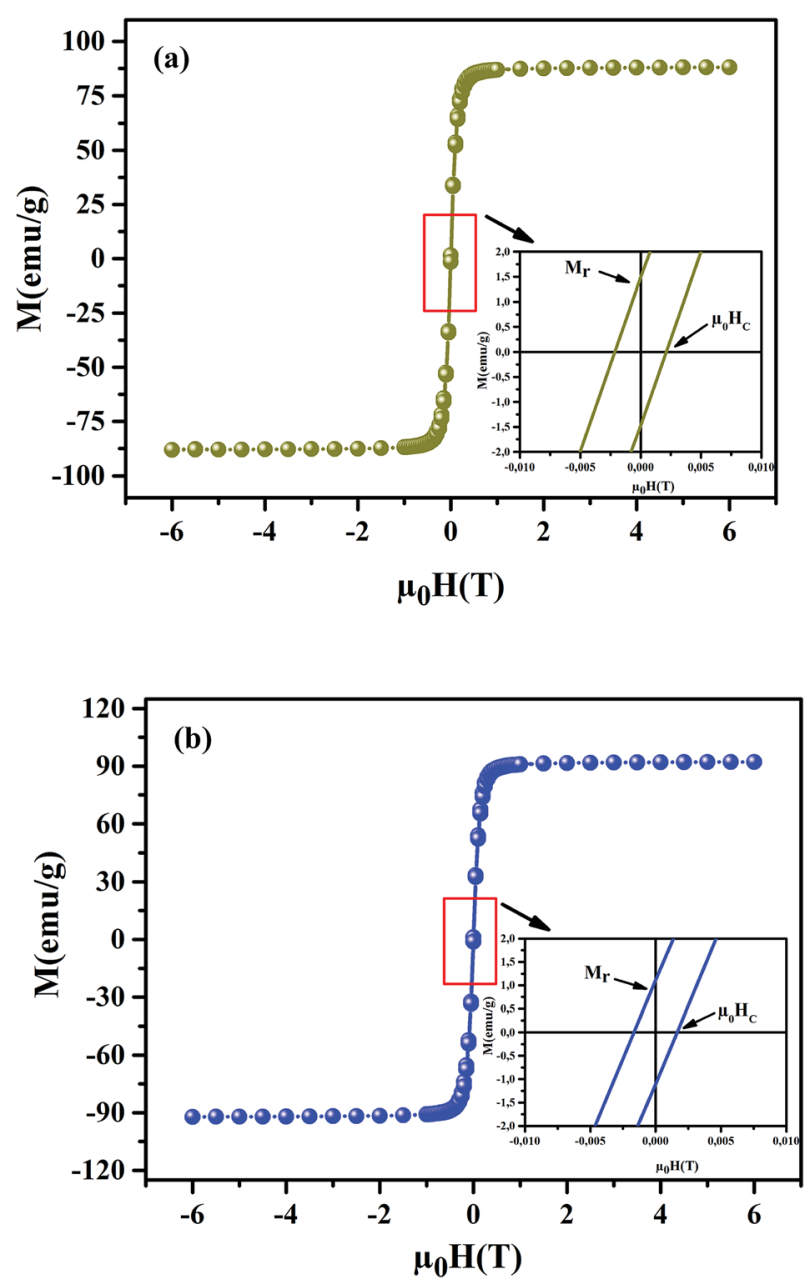

Fig. 5 Magnetic hysteresis cycles at $T=10 \mathrm{~K}$ of $\mathrm{La}_{0.75} \mathrm{Ca}_{0.25-x} \mathrm{Na}_{x}-$ $\mathrm{MnO}_{3}(x=0.15$ and 0.20$)$ samples. The insets show a zoom of the central portion of the hysteresis at a low field. 
temperatures, magnetization increased significantly and reached saturation upon increasing field. The saturation magnetization $\left(M_{\mathrm{S}}\right)$ was found to be 88.10 and $92.21 \mathrm{emu} \mathrm{g}^{-1}$, for $x=0.15$ and $x=0.20$, respectively. The insets of Fig. 5(a) and (b) show a zoom of the central portion, at low magnetic fields, of $M\left(\mu_{0} H\right)$ curves. It is clear that $M\left(\mu_{0} H\right)$ curves have negligible values of coercive field $\left(\mu_{0} H_{\mathrm{C}}\right)$ and remnant magnetization $\left(M_{\mathrm{r}}\right)$. $\mu_{0} H_{\mathrm{C}}$ values are found to be $21 \times 10^{-4}$ and $16 \times 10^{-4} \mathrm{~T}$, for $x=$ 0.15 and $x=0.20$, respectively. $M_{\mathrm{r}}$ values were found to be 1.49 and $1.11 \mathrm{emu}^{-1}$, for $x=0.15$ and $x=0.20$ respectively. The small hysteresis loop with important saturation values indicates the typical soft FM behavior of materials. According to these results, our samples could be used for reading and writing process in high density recording media or information storage. $^{42}$

Magneto-crystalline anisotropy is an intrinsic property of materials, playing an important role in coercivity. ${ }^{43}$ It is used to describe the effect of the internal energy on the direction of magnetization.

According to Stoner-Wohlfarth's theory, the anisotropy constant $\left(K_{\mathrm{a}}\right)$ can be determined from eqn $(4)^{\mathbf{4 4}}$

$$
\mu_{0} H_{\mathrm{C}}=\left(0.98 \times K_{\mathrm{a}}\right) / M_{\mathrm{S}}
$$

where $K_{\mathrm{a}}$ values are $188.7 \mathrm{~J} \mathrm{~m}^{-3}$ and $161.9 \mathrm{~J} \mathrm{~m}^{-3}$, for the $x=0.15$ and $x=0.20$ samples, respectively.

The remanence ratio $(R)$ using (eqn (5)):

$$
R=M_{\mathrm{r}} / M_{\mathrm{S}}
$$

is an important parameter, used to understand the isotropic nature of our studied samples. $R$ values are equal to 0.0169 and 0.0120 , for the $x=0.15$ and 0.20 samples, respectively. The small obtained values undergo the isotropic natures. ${ }^{45}$ Together with $M\left(\mu_{0} H\right)$ investigation; we have measured the isothermal magnetization as a function of applied magnetic fields up to $5 \mathrm{~T}$ at different temperatures, for our samples, around their $T_{\mathrm{C}}$ (inset of Fig. 6(a) and (b)). We can notice that these curves reveal a rapid increase in the magnetization at a very weak magnetic field corresponding to a quick rearrangement of the magnetic domains. This is due to the complete alignment of the spins in these samples from the value of the magnetic field, $1 \mathrm{~T}$. To clarify the nature of the magnetic phase transition, we derived the Arrott's plots $\left(M^{2}\right.$ vs. $\left.\mu_{0} H / M\right)$ from $\left.M\left(\mu_{0} H\right)\right)$. The obtained curves are shown in Fig. 6(a) and (b), for the $x=0.15$ and 0.20 samples. According to Banerjee's criterion, a positive slope corresponds to second order magnetic transition, while a negative slope corresponds to first order transition. ${ }^{46}$ From Fig. 6(a) and (b), we can see a positive slope without inflection points in the high-field regions for our samples. This indicates that our samples undergo a second order nature of phase FM-PM transition.

\subsection{Magnetocaloric properties}

For the determination of MCE especially in magnetic materials, both the experimental and theoretical approaches are used. However, for the theoretical investigation of MCE, several approaches were used. Recently, a theoretical model proposed
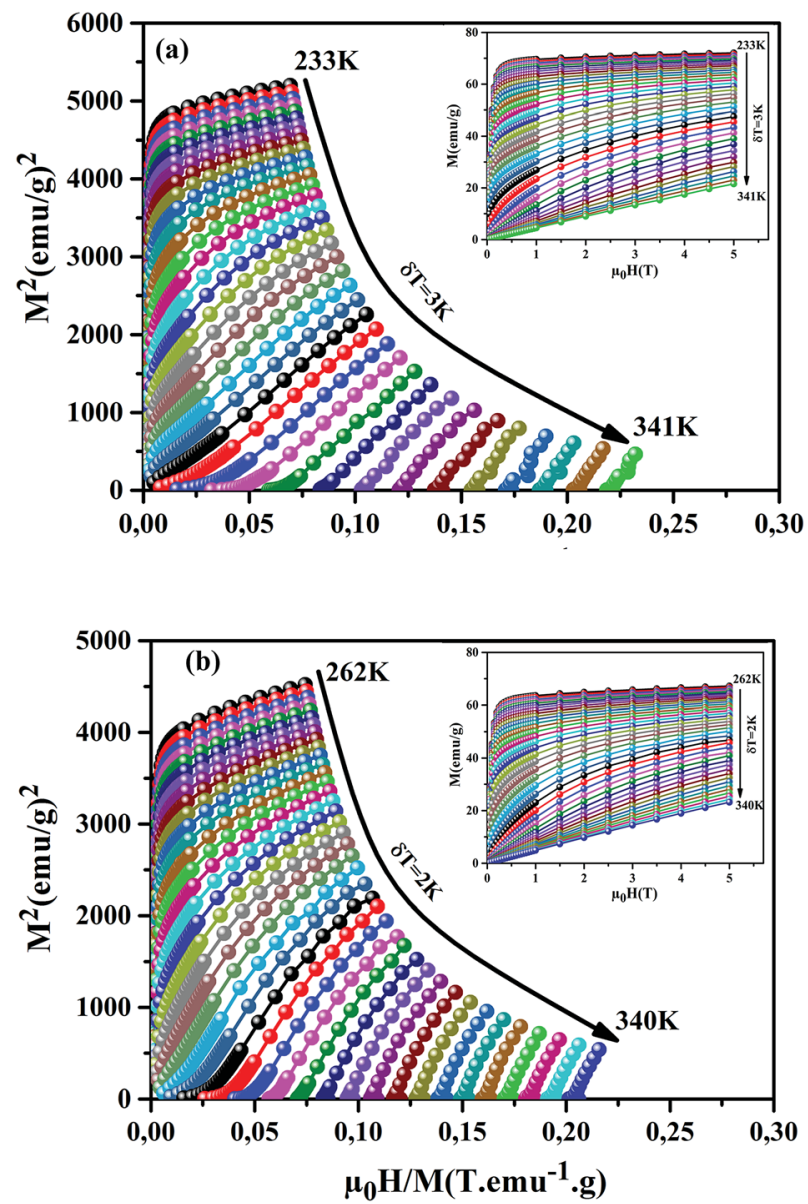

Fig. $6 M^{2}$ vs. $\mu_{0} H / M$ plots for our samples, around $T_{C}$. The insets show $M\left(\mu_{0} H\right)$ curves at different temperatures.

by Hamad ${ }^{47}$ began to receive attention. Based on this model, the dependence of magnetization on the temperatures is defined as:

$$
M=\left(\frac{M_{\mathrm{i}}-M_{\mathrm{f}}}{2}\right) \tanh \left[A\left(T_{\mathrm{C}}-T\right)\right]+B T+C
$$

where $M_{\mathrm{i}}$ and $M_{\mathrm{f}}$ are the initial and the final values of magnetization at FM-PM transition, respectively. $A=\frac{2\left(B-S_{\mathrm{C}}\right)}{M_{\mathrm{i}}-M_{\mathrm{f}}}, B$ is the magnetization sensitivity $\mathrm{d} M / \mathrm{d} T$ at FM state before transition. $S_{\mathrm{C}}$ is the magnetization sensitivity $\mathrm{d} M / \mathrm{d} T$ at $T_{\mathrm{C}}$. $C=\left(\frac{M_{\mathrm{i}}-M_{\mathrm{f}}}{2}\right)-B T_{\mathrm{C}}$.

According to this model, $-\Delta S_{\mathrm{M}}$ under applied magnetic fields in the range of 0 to $\mu_{0} H_{\max }$ is expressed by: ${ }^{48}$

$$
-\Delta S_{\mathrm{M}}(T)=\left(A\left(\frac{M_{\mathrm{i}}-M_{\mathrm{f}}}{2}\right) \operatorname{sech}^{2}\left(A\left(T_{\mathrm{C}}-T\right)\right)-B\right) \mu_{0} H_{\max }
$$

At $T=T_{\mathrm{C}}$, we obtained $-\Delta S_{\mathrm{M}}^{\max }$ value, defined as the following expression: ${ }^{49}$

$$
-\Delta S_{\mathrm{M}}^{\max }=\left(A\left(\frac{M_{\mathrm{i}}-M_{\mathrm{f}}}{2}\right)-B\right) \mu_{0} H_{\max }
$$


In magnetic refrigeration, it is important to take into account not only the $-\Delta S_{\mathrm{M}}$, but also the relative cooling power (RCP) as an important parameter which represents the amount of heat exchange per kilogram between the hot and cold sinks in the ideal refrigeration cycle. It is computed by: ${ }^{50}$

$$
\begin{aligned}
\mathrm{RCP} & =-\Delta S_{\mathrm{M}}^{\max } \times \delta T_{\mathrm{FWHM}} \\
& =\left(M_{\mathrm{i}}-M_{\mathrm{f}}-2 \frac{B}{A}\right) \mu_{0} H_{\max } \times \operatorname{sech}\left(\sqrt{\frac{2 A\left(M_{\mathrm{i}}-M_{\mathrm{f}}\right)}{A\left(M_{\mathrm{i}}-M_{\mathrm{f}}\right)+2 B}}\right)
\end{aligned}
$$

$\left(\delta T_{\text {FWHM }}\right)$ presents the full width at half maximum, defined as: ${ }^{48}$

$$
\delta T_{\text {FWHM }}=\frac{2}{A} \cosh ^{-1}\left(\frac{2 A\left(M_{\mathrm{i}}-M_{\mathrm{f}}\right)}{A\left(M_{\mathrm{i}}-M_{\mathrm{f}}\right)+2 B}\right)^{1 / 2}
$$

Another important parameter for magnetic refrigeration is the heat capacity $\Delta C_{\mathrm{P}, \mu_{0} H}$ associated with an applied magnetic field (1-5 T) can be determined by:

$$
\Delta C_{\mathrm{P}, \mu_{0} H}=T \frac{\partial \Delta S_{\mathrm{M}}}{\partial T}
$$

$\Delta C_{\mathrm{P}, \mu_{0} H}$ can be rewritten as: ${ }^{51}$

$$
\Delta C_{\mathrm{P}, \mu_{0} H}=-T A^{2}\left(M_{\mathrm{i}}-M_{\mathrm{f}}\right) \times \operatorname{sech}^{2}\left[A\left(T_{\mathrm{C}}-T\right)\right] \tanh \left[A\left(T_{\mathrm{C}}-T\right)\right]
$$$$
\mu_{0} H_{\max }
$$

In the rest of our work, the MCE properties for $x=0.15$ will be determined experimentally, while $x=0.20$ will be determined experimentally and theoretically.

Before studying the MCE properties of our samples, Fig. 7 represents $M(T)$ in different applied magnetic field, for $x=0.20$ sample. The symbol is the experimental data, while the solid red line is the modeled data (using eqn (6)). From $M(T)$, it is easy to determined $M_{\mathrm{i}}, M_{\mathrm{f}}, B$ and $S_{\mathrm{C}}$ parameters in order to investigate theoretically $-\Delta S_{\mathrm{M}}$, RCP, $-\Delta C_{\mathrm{P}, \mu_{0} H}$ and $\Delta T_{\mathrm{ad}}$ curves. The obtained parameters are summarized in Table 5 .

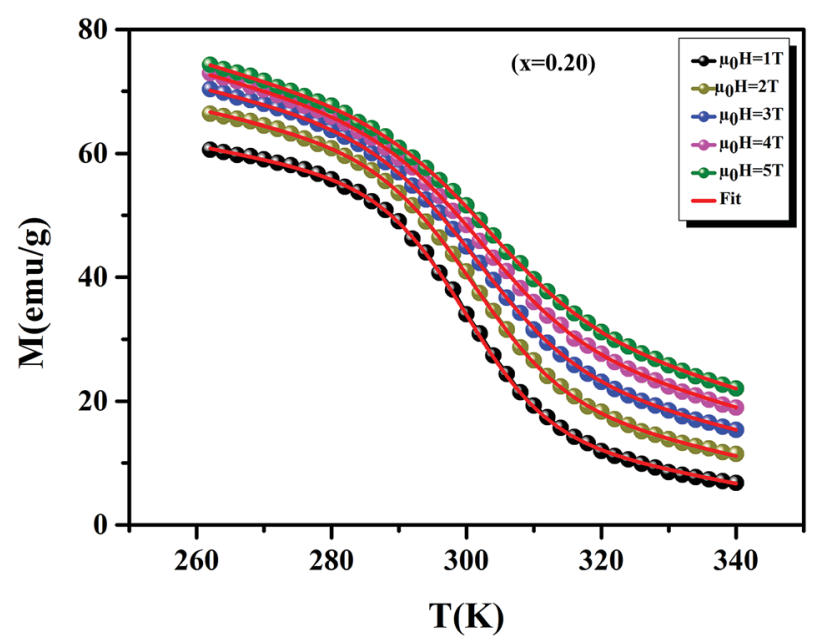

Fig. 7 Magnetization as function of temperatures under a magnetic fields, for $x=0.20$ sample. The red line curves represent the modeled data and symbols are the experimental data.
It is noteworthy that the theoretical model is in good agreement with the experimental data.

Fig. 8(a) and (b) shows the variation of $-\Delta S_{\mathrm{M}}$ as a function of temperature, under applied magnetic fields of 1-5 T, for the $x=$ 0.15 and 0.20 samples, respectively. For the $x=0.20$ sample, it is clear that the theoretical results (using eqn (7)) are consistent with the experimental results. This confirms the validity of this model. From Fig. 8, we can see a positive sign of $-\Delta S_{\mathrm{M}}$ in the entire temperature range, confirming the FM character. Around $T_{\mathrm{C}}$, the $x=0.20$ sample exhibited a classical behavior of $-\Delta S_{\mathrm{M}}$ with a maximum peak of $6.01 \mathrm{~J} \mathrm{~kg}^{-1} \mathrm{~K}^{-1}$ under $\mu_{0} H=5 \mathrm{~T}$ field. While, for the $x=0.15$ sample, we remarked the coexistence of two peaks. This corresponds to two-Curie temperatures. When studying the effect of $\mathrm{Ag}^{+}$in the $\mathrm{La}_{0.7} \mathrm{Ca}_{0.3} \mathrm{MnO}_{3}$ sample, Kalyana et al. have shown that the $x=0.10$ sample admits two magnetic transitions. This can be due to the existence of canted FM phase in the FM matrix. ${ }^{52} \mathrm{~A}$. Krichene et al. have shown that the $\mathrm{La}_{0.4} \mathrm{Gd}_{0.1} \mathrm{Ca}_{0.5} \mathrm{MnO}_{3}$ and $\mathrm{La}_{0.4} \mathrm{Eu}_{0.1} \mathrm{Ca}_{0.5} \mathrm{MnO}_{3}$ samples admit two maxima of $-\Delta S_{\mathrm{M}}$. The first one corresponds to $T_{\mathrm{C}}$. While, the second one is an anomaly, which explained as metamagnetic transition: in fact, PM and AFM transitions coexist above $T_{\mathrm{C}} \cdot{ }^{53}$ Hence, in our case the presence of two peaks in $-\Delta S_{\mathrm{M}}$ may be attributed to the combination of orthorhombic and rhombohedral structures in this sample. This is in agreement with that observed by Kima et al. ${ }^{54}$ The obtained $-\Delta S_{\mathrm{M}}^{\max }$ are comparable with those obtained in the literature (Table 6).

The different values of RCP for our samples are listed in Table 6. These parameters increase with increasing the external magnetic field. This is because the effect of spin coupling became less important when the applied magnetic field was increased. We can see that the proposed compounds exhibit important values. In addition, we can note that our samples can be considered as potential candidates for magnetic refrigeration thanks to their high RCP values, compared to conventional refrigerant materials (Table 6).

Using eqn (11) and (12), Fig. 9 display the experimental and the theoretical $\Delta C_{\mathrm{P}, \mu_{0} H}$ plots, for $x=0.20$ sample as an example. The symbol represents the experimental data, while the solid red line represents the modeled data. We can see clearly that the experimental results are in a good agreement with the calculated results. Additionally, we can remark that the value of $-\Delta C_{\mathrm{P}, \mu_{0} H}$ suddenly changed from positive to negative around $T_{\mathrm{C}}$. Then, it decreased rapidly with decreasing temperature. ${ }^{65}$ The sum of the two parts represents the magnetic contribution to the total specific heat. The positive or negative values of $\Delta C_{\mathrm{P}, \mu_{0} H}$ can strongly alter the heating or cooling power of a magnetic refrigerator. The obtained maximum/minimum values of $\Delta C_{\mathrm{P}, \mu_{0} H}$ at $315 / 293 \mathrm{~K}$, exhibited an increasing trend with the external magnetic field. It was found to be $63.98 /-62.62 \mathrm{~J} \mathrm{~kg}^{-1} \mathrm{~K}^{-1}$ at a $5 \mathrm{~T}$ applied magnetic field. Our results are comparable with those obtained in recent works. ${ }^{4}$

To have a wider understanding of the MCE properties, the adiabatic temperature change $\left(\Delta T_{\mathrm{ad}}\right)$ was calculated. It is defined as following: ${ }^{\mathbf{5 1}}$ 
Table 5 Model parameters for $\mathrm{La}_{0.75} \mathrm{Ca}_{0.25-x} \mathrm{Na}_{x} \mathrm{MnO}_{3}(x=0.15$ and 0.20$)$ compounds in different applied magnetic fields

\begin{tabular}{lllll}
\hline$\mu_{0} H(\mathrm{~T})$ & $M_{\mathrm{i}}\left(\mathrm{emu} \mathrm{g}^{-1}\right)$ & $M_{\mathrm{f}}\left(\mathrm{emu} \mathrm{g}^{-1}\right)$ & $B\left(\mathrm{emu} \mathrm{g}^{-1} \mathrm{~K}^{-1}\right)$ & $S_{\mathrm{C}}\left(\mathrm{emu} \mathrm{g}^{-1} \mathrm{~K}^{-1}\right)$ \\
\hline 1 & 49.60 & 11.25 & -0.204 & -1.772 \\
2 & 53.75 & 16.17 & -0.233 & -1.597 \\
3 & 58.66 & 22.73 & -0.247 & -1.365 \\
4 & 62.48 & 31.39 & -0.294 & -1.321 \\
5 & 63.59 & 34.57 & -0.303 & -1.286
\end{tabular}

$$
\begin{aligned}
\Delta T_{\mathrm{ad}}\left(T, \Delta \mu_{0} H\right. & \left.=\mu_{0} H_{\max }\right)=-\frac{T}{C_{\mathrm{P}, \mu_{0} H}} \int_{0}^{\mu_{0} H_{\max }}\left[\frac{\partial M}{\partial T}\right]_{\mu_{0} H} \mathrm{~d} \mu_{0} H \\
& =-\frac{T}{C_{\mathrm{P}, \mu_{0} H}} \Delta S_{\mathrm{M}}
\end{aligned}
$$

Taking into account the eqn (6) in eqn (13) $\Delta T_{\text {ad }}$ can be rewritten as:

$$
\begin{aligned}
\Delta T_{\mathrm{ad}}(T, \Delta H & \left.=\mu_{0} H_{\max }\right) \\
& =\frac{A T\left(M_{\mathrm{i}}-M_{\mathrm{f}}\right)}{2 C_{\mathrm{P}, \mu_{0} H}}\left[\operatorname{sech}^{2}\left(A\left(T_{\mathrm{C}}-T\right)\right)+B\right] \mu_{0} H_{\max }
\end{aligned}
$$
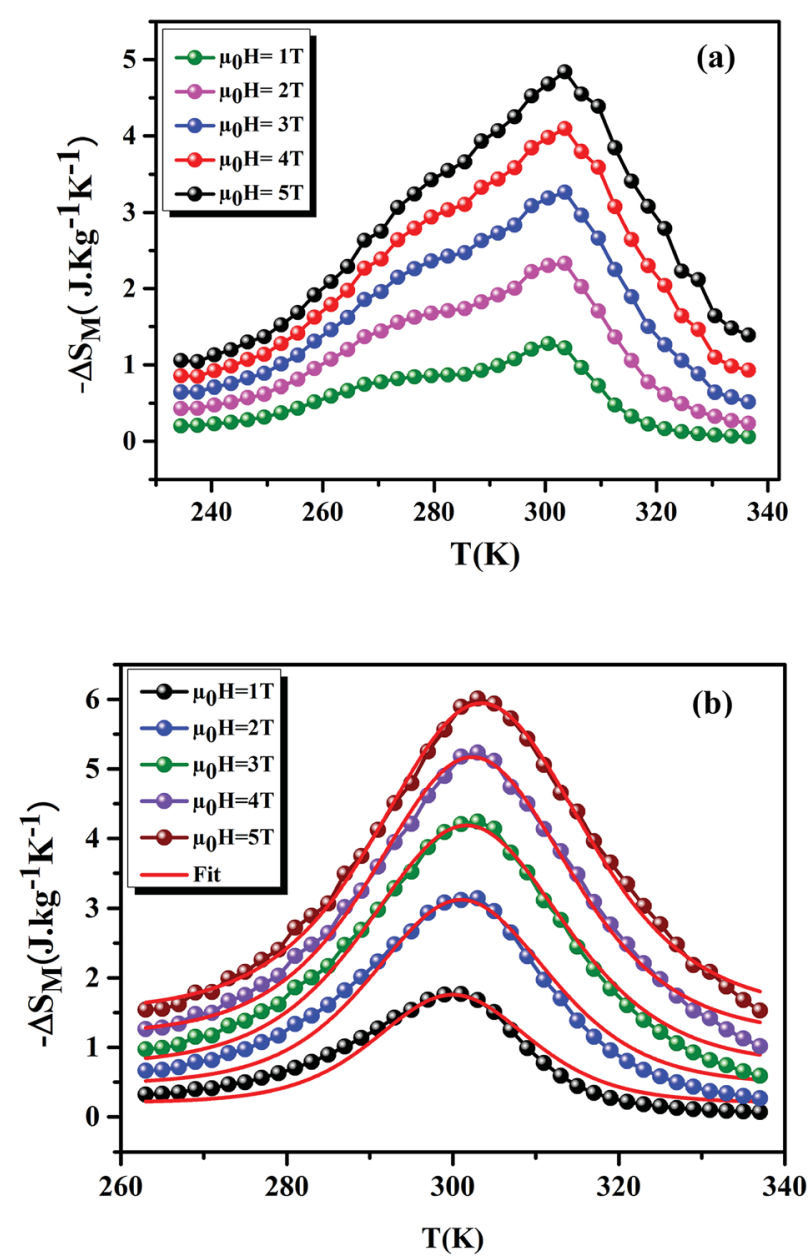

Fig. $8-\Delta S_{M}$ as a function of temperature at different $\mu_{0} H$ fields, for $x$ $=0.15$ and 0.20 compounds. The red line curves represent the modeled data and symbols are the experimental data.
$C_{\mathrm{P}, \mu_{0} H}$ represents the specific heat, it can be calculated from the sum of the lattice and magnetic contributions using eqn $(15)^{66,67}$

$$
C_{\mathrm{P}, H}=C_{\mathrm{D}}+C_{\mathrm{M}}
$$

where $C_{\mathrm{D}}$ is the Debye specific heat and $C_{\mathrm{M}}$ is the magnetic contribution to the specific heat capacity). $C_{\mathbf{M}}$ is given by $\left(\partial U_{\mathbf{M}} /\right.$ $\partial T$ ), and is determined from: ${ }^{66,67}$

$$
C_{\mathrm{M}}=-H_{\mathrm{ext}} \frac{\partial M}{\partial T}-\frac{1}{2} N_{\mathrm{int}} \frac{\partial M^{2}}{\partial T}
$$

where $N_{\text {int }}$ presents the mean field constant. It is equal to $\frac{3 K T_{C}}{N_{\mathrm{S}} g^{2} \mu_{\mathrm{B}}^{2} J(J+1)}, g$ is the Landé factor, $J$ is the total angular momentum and $N_{\mathrm{S}}$ is the number of spins per unit mass.

Using eqn (13) and (14), Fig. 10(a) and (b) shows the experimental and theoretical curves of $\Delta T_{\mathrm{ad}}$ for our samples, respectively. The symbol represents the experimental data, while the solid red line refers to the modeled data. It is obvious that the results of calculation are in good agreement with the experimental results. Also, it is clear that $\Delta T_{\mathrm{ad}}$ maintains practically the nature of $-\Delta S_{\mathrm{M}}$. The maximum values of $\Delta T_{\mathrm{ad}}$ range from 2.93 and $3.64 \mathrm{~K}$ at $5 \mathrm{~T}$, for $x=0.15$ and 0.20 , respectively.

A phenomenological universal curve for the field dependence of $-\Delta S_{\mathrm{M}}$ has been proposed, by Franco et al. ${ }^{68}$ It is based on the normalization of all $-\Delta S_{\mathrm{M}}\left(T, \mu_{0} H\right)$ curves using eqn 17

$$
\Delta S^{\prime}=\Delta S_{\mathrm{M}}\left(T, \mu_{0} H\right) / \Delta S_{\mathrm{M}}^{\max } .
$$

After that, the temperatures' axes are differently rescaled below and above $T_{\mathrm{C}}$, defined as (eqn (18)): ${ }^{\mathbf{9}}$

$$
\theta= \begin{cases}\frac{T-T_{\mathrm{C}}}{T_{\mathrm{C}}-T_{\mathrm{r}_{1}}} & T \leq T_{\mathrm{C}} \\ \frac{T-T_{\mathrm{C}}}{T_{\mathrm{r}_{2}}-T_{\mathrm{C}}} & T \geq T_{\mathrm{C}}\end{cases}
$$

where, $T_{\mathrm{r}_{1}}$ and $T_{\mathrm{r}_{2}}$ are the temperatures of two reference points, associated to $\Delta S_{\mathrm{M}}\left(T_{\mathrm{r}_{1,2}}\right)=-\Delta S_{\mathrm{M}}^{\max } / 2\left(T_{\mathrm{r}_{1}}<T_{\mathrm{C}}\right.$ and $\left.T_{\mathrm{r}_{2}}>T_{\mathrm{C}}\right)$. Fig. 11 displays the $\theta$ dependence of $\Delta S^{\prime}$ under different magnetic fields, for the $x=0.20$ sample, as an example. It is clearly seen that all data points collapse on one single curve. Therefore, the FM-PM phase transition in our sample was confirmed to be of second order nature. ${ }^{70}$

The universal curve can be well fitted by Lorentz's function using (eqn (19)):

$$
\Delta S^{\prime}=\frac{a}{b+(\theta-c)^{2}}
$$


Table 6 Summary of $\mathrm{MC}$ properties of $\mathrm{La}_{0.75} \mathrm{Ca}_{0.25-x} \mathrm{Na}_{x} \mathrm{MnO}_{3}(x=0.15$ and 0.20$)$ compounds compared with other works

\begin{tabular}{|c|c|c|c|c|c|}
\hline Samples & $T_{\mathrm{C}}(\mathrm{K})$ & $\begin{array}{l}\mu_{0} H \\
(\mathrm{~T})\end{array}$ & $-\Delta S_{\mathrm{M}}^{\max }\left(\mathrm{J} \mathrm{kg}^{-1} \mathrm{~K}^{-1}\right)$ & $\operatorname{RCP}\left(\mathrm{J} \mathrm{kg}^{-1}\right)$ & Ref. \\
\hline $\mathrm{La}_{0.75} \mathrm{Ca}_{0.10} \mathrm{Na}_{0.15} \mathrm{MnO}_{3}$ & 301.5 & 5 & 4.83 & 230 & Present work \\
\hline $\mathrm{La}_{0.75} \mathrm{Ca}_{0.05} \mathrm{Na}_{0.20} \mathrm{MnO}_{3}$ & 300 & 5 & 6.01 & 225 & Present work \\
\hline $\mathrm{La}_{0.75} \mathrm{Ca}_{0.05} \mathrm{Na}_{0.20} \mathrm{MnO}_{3}$ & - & 2 & 3.12 & 90 & Present work \\
\hline $\mathrm{La}_{0.5} \mathrm{Sm}_{0.1} \mathrm{Sr}_{0.4} \mathrm{Mn}_{0.95} \mathrm{In}_{0.05} \mathrm{O}_{3}$ & 294 & 5 & 4.50 & 193.48 & 55 \\
\hline $\mathrm{Gd}$ & 293 & 2 & 5 & 153 & 57 \\
\hline Gd & 293 & 5 & 9.5 & 410 & 58 \\
\hline $\mathrm{La}_{0.57} \mathrm{Nd}_{0.1} \mathrm{Sr}_{0.33} \mathrm{Mn}_{0.95} \mathrm{Sn}_{0.05} \mathrm{O}_{3}$ & 281 & 5 & 2.8 & 51 & 59 \\
\hline $\mathrm{La}_{0.7} \mathrm{Sr}_{0.3} \mathrm{Mn}_{0.95} \mathrm{Ti}_{0.05} \mathrm{O}_{3}$ & 308 & 2 & 2.2 & 90 & 60 \\
\hline $\mathrm{La}_{0.8} \mathrm{Ba}_{0.2} \mathrm{MnO}_{3}$ & 295 & 5 & 4.5 & 130 & 61 \\
\hline $\mathrm{La}_{0.7} \mathrm{Sr}_{0.3} \mathrm{Mn}_{0.9} \mathrm{Fe}_{0.1} \mathrm{O}_{3}$ & 260 & 2 & 1.7 & 83 & 62 \\
\hline
\end{tabular}

where $a, b$, and $c$ are free parameters. Taking into consideration the asymmetry of the curves (for $x=0.20$ as an example), we can use two different regions of constants such as: for $T<T_{\mathrm{C}}$ region, $a=1.458 \pm 0.037, b=1.391 \pm 0.026$ and $c=0.174 \pm 0.021$. While, for $T>T_{\mathrm{C}}$ region, $a=0.717 \pm 0.046 ; b=0.743 \pm 0.048$ and $c=0.122 \pm 0.030$. Our obtained parameters are comparable to those obtained in ref. 71. According to eqn (19), only the different parameters namely $T_{\mathrm{C}},-\Delta S_{\mathrm{M}}^{\max }, T_{\mathrm{r}_{1}}$ and $T_{\mathrm{r}_{2}}$ values are needed to characterize $-\Delta S_{\mathrm{M}}$. That is to say, we need only the last parameters, which are determined from the properties of these materials, to determine $-\Delta S_{\mathrm{M}}$ from $\Delta S^{\prime}(\theta)$.

Generally, $-\Delta S_{\mathrm{M}}$ is dependent on the variation of magnetization near $T_{\mathrm{C}}$. It can be expressed by: ${ }^{72}$

$$
\Delta S_{\mathrm{M}}\left(T, \mu_{0} H\right)=a(T)\left(\mu_{0} H\right)^{n}
$$

where $n$ is an exponent which depends on the magnetic transition and defined as: ${ }^{73}$

$$
n\left(T, \mu_{0} H\right)=\frac{\mathrm{d} \ln \left(\left|\Delta S_{\mathrm{M}}\right|\right)}{\mathrm{d} \ln \left(\mu_{0} H\right)}
$$

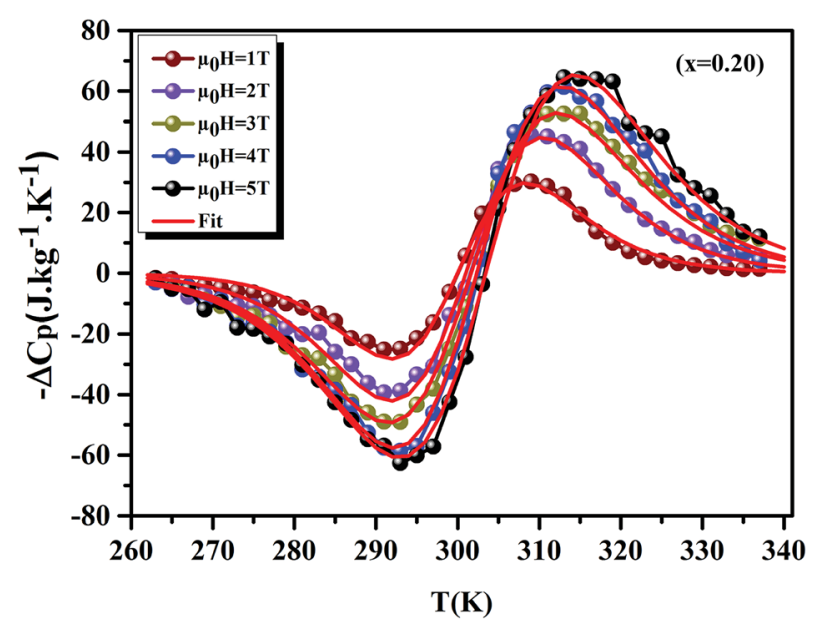

Fig. 9 Experimental and theoretical curves of $\Delta C_{P}$ versus temperatures for $x=0.20$ compounds under different magnetic fields.
Fig. 12 displays the variation of $n$ as function of temperatures, under different applied fields, for the $x=0.20$ sample. We can see that the value of $n$ approaches 1 in the FM region and admits a minimum in $T_{\mathrm{C}}$. Then, it approaches 2 in the PM state. These results are observed in different magnetic materials. ${ }^{74-76}$
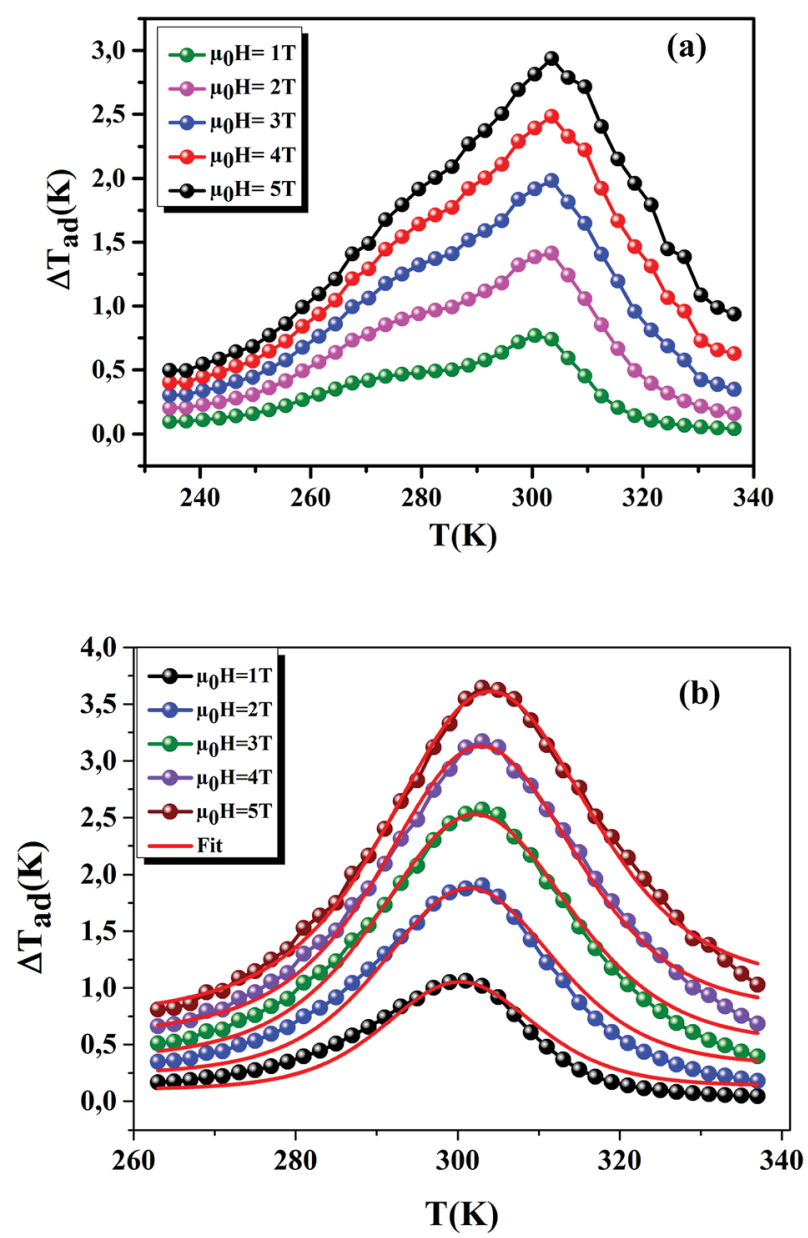

Fig. $10 \Delta T_{\text {ad }}$ plotted as a function of temperature at different $\mu_{0} H$ fields, for $x=0.15$ and 0.20 compounds. The red line curves represent the modeled data and symbols are the experimental data. 


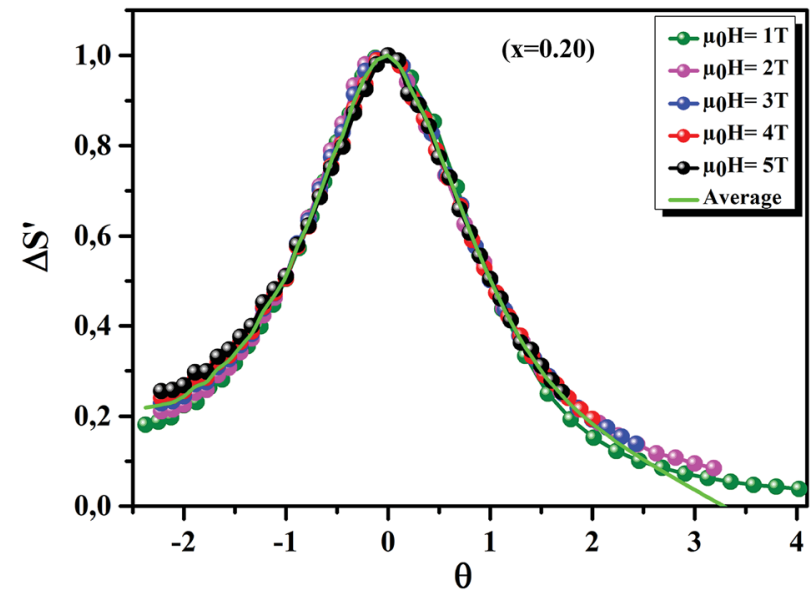

Fig. 11 The universal behavior of $\Delta S^{\prime}(\theta)$ plots for $x=0.20$ sample, under different magnetic fields.

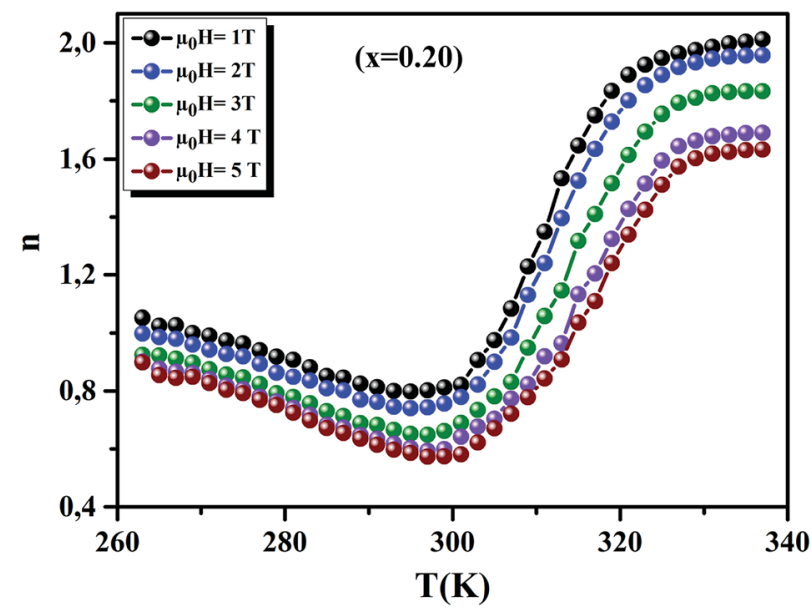

Fig. 12 Temperature dependence of the exponent $n$, for $x=0.20$, under different magnetic fields.

\section{Conclusion}

In summary, we have investigated the structural, morphological, magnetic and MCE properties of $\mathrm{La}_{0.75} \mathrm{Ca}_{0.25-x} \mathrm{Na}_{x} \mathrm{MnO}_{3}(x$ $=0.15$ and 0.20$)$ samples, synthesized using the flux method. Rietveld refinement of XRD patterns shows that $x=0.20$ crystallized in a rhombohedral structure with $R \overline{3} c$ space group, at room temperature. While, the $x=0.15$ sample admits both phases with different percentages. Magnetization measurements as function of temperatures in a magnetic field of $0.05 \mathrm{~T}$ show that our studied samples undergo a second-order PM-FM phase transition, upon decreasing temperature. Around room temperature, a large MCE is observed for our samples, under a magnetic field of 5 T. $-\Delta S_{\mathrm{M}}^{\max }$ is found to be $6.01 \mathrm{~J} \mathrm{~kg}^{-1} \mathrm{~K}^{-1}$ under $\mu_{0} H=5 \mathrm{~T}$ magnetic field for $x=0.20$. For the $x=0.15$ sample, $-\Delta S_{\mathrm{M}}$ curves show the existence of two maxima, which may be attributed to the structural inhomogeneity. The RCP is also analyzed. From, $-\Delta S_{\mathrm{M}}$ curves, we have investigated the dependence of temperature on the adiabatic temperature change ( $\left.-\Delta T_{\text {ad }}\right)$. Its maximum is found to be $2.93 \mathrm{~K}$, for the $x=$ 0.15 sample, in an applied magnetic field of $5 \mathrm{~T}$. From the hysteresis cycles, at $10 \mathrm{~K}$ for the studied samples, we can remark a typical soft FM behavior with a small hysteresis loop and a low coercive field $\left(\mu_{0} H_{\mathrm{C}}\right)$. The small values of coercive field confirm that the magnetic domains can rotate easily to the direction of the applied magnetic field. These results make our samples promising candidates for magnetic refrigeration, magnetic recording and memory devices.

\section{Conflicts of interest}

The authors declare that they have no conflict of interest.

\section{References}

1 T. L. Phan, T. A. Ho, P. D. Thang, Q. T. Tran, T. D. Thanh, N. X. Phuc, M. H. Phan, B. T. Huy and S. C. Yu, J. Alloys Compd., 2014, 615, 937-945.

2 T. A. Ho, T. L. Phan, P. D. Thang and S. C. Yu, J. Electron. Mater., 2016, 45, 2328-2333.

3 M. A. Gdaiem, Ah. Dhahri, J. Dhahri and E. K. Hlil, Mater. Res. Bull., 2017, 88, 91-97.

4 A. Belkahla, K. Cherif, J. Dhahri and E. K. Hlil, J. Alloys Compd., 2017, 715, 266-274.

5 R. Skini, A. Omri, M. Khlifi, E. Dhahri and E. K. Hlil, J. Magn. Magn. Mater., 2014, 364, 5-10.

6 Y. C. Kim, K. H. Kim, D. Y. Son, D. N. Jeong, J. Y. Seo, Y. S. Choi, I. T. Han, S. Y. Lee and N. G. Park, Nature, 2017, 550, 87-91.

7 J. Khelifi, A. Tozri, F. Issaoui, E. Dhahri and E. K. Hlil, J. Alloys Compd., 2014, 584, 617-624.

8 C. Zener, Phys. Rev., 1951, 81, 440-444.

9 J. B. Goodenough, J. Appl. Phys., 1997, 81, 5330-5335.

10 P. Levy, F. Parisi, G. Polla, D. Vega, G. Leyva and H. Lanza, Phys. Rev. B: Condens. Matter Mater. Phys., 2000, 62, 64376441.

11 K. H. Ahn, X. W. Wu, K. Liu and C. L. Chien, J. Appl. Phys., 1997, 81, 5505-5507.

12 M. Pissas and G. Kallias, Phys. Rev. B: Condens. Matter Mater. Phys., 2003, 68, 134414-134422.

13 M. Pekala, V. Drozd and J. Mucha, J. Magn. Magn. Mater., 2005, 928-932.

14 T. Yi, S. Gao, X. Qi, Y. Zhu, F. Cheng, B. Ma, Y. Huang and C. Yan, J. Phys. Chem. Solids, 2000, 61, 1407-1413.

15 M. Baldini, et al., J. Phys.: Condens. Matter, 2012, 24, 045601045605.

16 W. Zhong, W. Cheng, W. P. Ding, N. Zhang, Y. W. Du and Q. J. Yan, Solid State Commun., 1998, 106, 55-58.

17 D. B. Wiles and R. A. Young, J. Appl. Crystallogr., 1981, 14, 149-151.

18 M. Koubaa, W. Cheikhrouhou-Koubaa and A. Cheikhrouhou, J. Phys. Chem. Solids, 2009, 70, 326-333.

19 S. Choura-Maatar, R. Mnassri, W. Cheikhrouhou-Koubaa, M. Koubaa, A. Cheikhrouhou and E. K. Hlil, J. Magn. Magn. Mater., 2017, 433, 239-247. 
20 M. Khlifi, M. Bejar, O. El Sadek, E. Dhahri, M. A. Ahmed and E. K. Hlil, J. Alloys Compd., 2011, 509, 7410-7415.

21 R. D. Shannon, Acta Crystallogr., Sect. A: Cryst. Phys., Diffr., Theor. Gen. Crystallogr., 1976, 32, 751-767.

22 K. Momma and F. Izumi, J. Appl. Crystallogr., 2011, 44, 12721276.

23 Z. Wei, A. Chak-Tong and D. Y. Wei, Chin. Phys. B, 2013, 22, 057501.

24 P. Schiffer, A. P. Ramirez, K. N. Franklin and S.-W. Cheon, Phys. Rev. Lett., 1996, 77, 2085-2088.

25 H. L. Ju, H. C. Sohn and K. M. Krishnan, Phys. Rev. Lett., 1997, 79, 3230-3233.

26 K. Cherif, A. Belkahla, A. Dhahri and J. Dhahri, J. Supercond. Novel Magn., 2015, 28, 2241-2248, DOI: 10.1007/s10948-0153070-1.

27 R. Thaljaoui, W. Boujelben, M. Pękała, K. Pękała, J. Antonowicz, J.-F. Fagnard, P. Vanderbemden, S. Dą browska and J. Mucha, J. Alloys Compd., 2014, 611, 427-432.

28 G. Lalitha and P. Venugopal Reddy, J. Magn. Magn. Mater., 2008, 320, 754-759.

29 A. Taylor, X-Ray Metallography, Wiley, New York, 1961.

30 N. Kallel, S. Kallel, O. Pena and M. Oumezzine, Solid State Sci., 2009, 11, 1494-1498.

31 C. V. Vazquez, M. C. Blanco, M. A. L. Quintela, R. D. Sanchez, J. Rivas and S. B. Oseroff, J. Mater. Chem., 1998, 8, 991-1000.

32 J. Gutierrez, A. Pena, J. M. Barandiran, J. L. Pizarro, T. Hernandez, L. Lezama, M. Insausti and T. Rojo, Phys. Rev. B: Condens. Matter Mater. Phys., 2000, 61, 9028-9035.

33 W. Boujelben, A. Cheikh-Rouhou and J. C. Joubert, Eur. Phys. J. B, 2001, 24, 419-423.

34 L. Q. Zheng and Q. F. Fang, Phys. Status Solidi A, 2001, 185, 267-275.

35 A. Zaidi, K. Cherif, J. Dhahri, E. K. Hlil, M. Zaidi and T. Alharbi, J. Alloys Compd., 2015, 650, 210-216.

36 M. Medarde, J. Mesot, P. Lacorre, S. Rosenkranz, P. Fischer and K. Gobrecht, Phys. Rev. B: Condens. Matter Mater. Phys., 1995, 52, 9248-9258.

37 A. H. Morrish, The Physical Principles of Magnetism, IEEE Press, New York, 2001.

38 S. Mnefgui, A. Dhahri, N. Dhahri, El. K. Hlil and J. Dhahri, J. Magn. Magn. Mater., 2013, 340, 91-96.

39 R. P. Borges, F. Ott, R. M. Thomas, V. Skumryev, J. M. D. Coey, J. I. Arnaudas and L. Ranno, Phys. Rev. B: Condens. Matter Mater. Phys., 1999, 60, 12847-12851.

40 A. Belkahla, K. Cherif, J. Dhahri, K. Taibi and E. K. Hlil, RSC Adv., 2017, 7, 30707-30716.

41 M. Baazaoui, N. Hamdaoui, M. R. Laouyenne, W. Cheikhrouhou-Koubaa, L. Beji and M. Oumezzine, $J$. Supercond. Novel Magn., 2017, 30, 2763-2770.

42 K. El Maalam, M. Ben Ali, H. El Moussaoui, O. Mounkachi, M. Hamedoun, R. Masrour, E. K. Hlil and A. Benyoussef, $J$. Alloys Compd., 2015, 622, 761-764.

43 S. S. Nair, M. Mathews, P. A. Joy, S. D. Kulkarni and M. R. Anantharaman, J. Magn. Magn. Mater., 2004, 283, 344-352.
44 S. J. Haralkar, R. H. Kadam, S. S. More, S. E. Shirsath, M. L. Mane, S. Patil and D. R. Mane, Phys. B, 2012, 407, 4338-4346.

45 S. Thankachan, B. P. Jacob, S. Xavier and E. M. Mohammed, Phys. Scr., 2013, 87, 1-7.

46 B. K. Banerjee, Phys. Lett., 1964, 12, 16-17.

47 M. A. Hamad, Phase Transitions, 2012, 85, 106-112.

48 N. P. Kumar, G. Lalitha, E. Sagar and P. V. Reddy, Phys. B, 2015, 457, 275-279.

49 M. S. Anwar, F. Ahmed and B. H. Koo, J. Alloys Compd., 2014, 617, 893-898.

50 R. Cherif, E. K. Hlil, M. Ellouze, F. Elhalouani and S. Obbade, J. Mater. Sci., 2014, 49, 8244-8251.

51 M. A. Hamad, J. Supercond. Novel Magn., 2014, 27, 277-280.

52 Y. K. Lakshmi and P. V. Reddy, Solid State Sci., 2010, 12, 1731-1740.

53 A. Krichene, W. Boujelben and A. Cheikhrouhou, J. Alloys Compd., 2013, 550, 75-82.

54 J. S. Kim, A. N. Ulyanov, Y. M. Kang, S. G. Min, S. C. Yu and S. I. Yoo, J. Magn. Magn. Mater., 2007, 310, 2818-2819, DOI: 10.1016/j.jmmm.2006.10.964.

55 M. Dhahri, A. Zaidi, K. Cherif, J. Dhahri and E. K. Hlil, J. Alloys Compd., 2017, 691, 578-586.

56 M. Oumezzine, S. Zemni and O. Pena, J. Alloys Compd., 2010, 508, 292-296.

57 E. Brück, O. Tegus, D. T. C. Thanh and K. H. J. Buschow, J. Magn. Magn. Mater., 2007, 310, 2793-2799.

58 K. A. Gschneidner Jr, V. K. Pecharsky and A. O. Tsokol, Rep. Prog. Phys., 2005, 68, 1479-1539.

59 E. Tka, K. Cherif and J. Dhahri, Appl. Phys., 2014, 116, 11811191.

60 D. I. N. H. Nam, N. V. Dai, L. V. Hong, N. X. Phuc, S. C. Yu, M. Tachibana and E. Takayama-Muromachi, J. Appl. Phys, 2008, 103, 043905-043909.

61 S. Ghodhbane, A. Dhahri, N. Dhahri, E. K. Hlil and J. Dhahri, J. Alloys Compd., 2013, 550, 358-364.

62 S. K. Barik, C. Krishnamoorthi and R. Mahendiran, J. Magn. Magn. Mater., 2011, 323, 1015-1021.

63 Za. Mohamed, M. Abassi, E. Tka, J. Dhahri and E. K. Hlil, J. Alloys Compd., 2015, 646, 23-31.

64 M. H. Phan, S. C. Yu and N. H. Hur, Appl. Phys. Lett., 2005, 86, 072504.

65 A. Ben Hassine, A. Dhahri, L. Bouazizi, M. Oumezzine and E. K. Hlil, Solid State Commun., 2016, 233, 6-10.

66 A. H. Morrish, The Physical Principle of Magnetism,John Wiley \& Sons, Inc., New York, 1965.

67 N. W. Ashcroft and N. D. Mermin, Solid State Physics, London:Saunders College Publishing, 1976.

68 V. Franco, J. S. Blázquez and A. Conde, Appl. Phys. Lett., 2006, 89, 222512.

69 V. Franco and A. Conde, Int. J. Refrig., 2010, 33, 465-473.

70 Q. Y. Dong, H. W. Zhang, J. R. Sun, B. G. Shen and V. Franco, J. Appl. Phys., 2008, 103, 116101-116103.

71 A. Ben Jazia Kharrat, E. K. Hlil and W. Boujelben, J. Alloys Compd., 2018, 739, 101-113.

72 T. D. Shen, R. B. Schwarz, J. Y. Coulter and J. D. Thompson, J. Appl. Phys., 2002, 91, 5240-5245. 
73 V. Franco, A. Conde, E. J. M. Romero and J. S. Blazquez, J. Phys.: Condens. Matter, 2008, 20, 285207-285211.

74 C. P. Reshmi, S. Savitha Pillai, M. Vasundhara, G. R. Raji, K. G. S uresh and M. Raama Varma, J. Appl. Phys., 2013, 114, 033904-033910.
75 V. Franco, C. F. Conde, J. S. Blazquez, A. Conde, P. Svec, D. Janičkovic and L. F. Kiss, J. Appl. Phys., 2007, 101, 093903. 76 P. Nisha, S. Savitha Pillai, M. RaamaVarma and K. G. Suresh, Solid State Sci., 2012, 14, 40-47. 